\title{
A new species of Sycorax (Diptera: Psychodidae: Sycoracinae) from the Brazilian Atlantic Forest
}

\author{
Freddy Bravo'; Leonardo de Souza Rocha² \& Claudiney Biral dos Santos²
}

\author{
1 Departamento de Ciências Biológicas, Universidade Estadual de Feira de Santana. Avenida Transnordestina, \\ 44036-900 Feira de Santana, BA, Brazil; E-mail: fbravo@uefs.br \\ 2 Unidade de Medicina Tropical, Universidade Federal do Espírito Santo. Avenida Marechal Campos 1468, \\ 29040-090 Vitória, ES, Brazil; E-mail: claudiney@ppgcf.ufes.br; Isr@ioc.fiocruz.br
}

\begin{abstract}
Sycorax confusa sp. nov. is described from the Atlantic Forest of the state of Espírito Santo, Brazil. The new species has a paramere with a long bristle, a characteristic that had only been observed in Sycorax longispinosa Bravo, 2007 from the Brazilian Amazon; the new species can be differentiated from the last one because the middle acute internal projections of each paramere do not cross each other and because the anterior end of aedeagal apodeme is bulbous. A key to the species of Sycorax Haliday in Curtis, 1839 (males) from the Neotropical Region is provided.
\end{abstract}

KEY WORDS. Neotropical Region, Brazil, moth fly, new species.

Sycorax Haliday in Curtis, 1839 sensu Duckhouse (1972) includes 32 species (Ježek 1999, Bravo 2003, 2007, Bravo \& Salazar-Valenzuela 2009, Santos \& Bravo 2009), ten from the Neotropical Region. Five species are currently known from Brazil (Barretto 1956, Bravo 2003, 2007, Santos \& Bravo 2009): Sycorax assimilis Barretto, 1956 from the state of São Paulo; S. bahiensis Bravo, 2003 from the state of Bahia; S. cariacicaensis Santos \& Bravo, 2009 and S. espiritosantensis Santos \& Bravo, 2009 from the state of Espírito Santo; and S. longispinosa Bravo, 2007 from the state of Pará.

During routine entomological surveillance for leishmaniasis control in the municipality of Afonso Cláudio, Espírito Santo, Brazil, three specimens of a new species of Sycorax were collected and are described here. A key to the Neotropical species of Sycorax (males) is also provided.

The specimens were collected with CDC light traps, cleared with $10 \% \mathrm{KOH}$ and mounted in Berlese's medium according to the methodology described by BARRETTO \& COUTINHO (1940). The morphological terminology used in the descriptions is the same of Bravo \& Salazar-Valenzuela (2009). The specimens were deposited in the Coleção Entomológica Prof. Johann Becker, Museu de Zoologia, Universidade Estadual de Feira de Santana, Feira de Santana, state of Bahia, Brazil (MZUEFS).

\section{TAXONOMY}

\section{Sycorax confusa sp. nov.}

Figs 1-9

Type material. BrazIL, Espírito Santo: Afonso Cláudio municipality (Empoçado, $20^{\circ} 03,576^{\prime} \mathrm{S}, 41^{\circ} 10,062^{\prime} \mathrm{W}, 132 \mathrm{msl}$ ), 04.VIII.2008, C.B. Santos leg., holotype male (\#43949, MZUEFS); two paratype males with the same data as the holotype (\#43950 and \#43951, MZUEFS).

Diagnosis. First flagellomere 1.8 times as long as second; gonocoxite 1.4 times as long as gonostylus; gonostylus with one apical spine; paramere with long, thick apical bristle, twice as long as paramere; aedeagus bifid without pair of lateral sclerotinized projections; anterior end of aedeagal apodeme bulbous.

Description. Male. Eyes separated, without eye bridge; clypeus rectangular; labrum triangular, 1.5 times as long as clypeus; antenna damaged (incomplete) in all specimens; scape smaller than pedicel (Fig. 1); pedicel spherical (Fig. 1); pedicel twice as long as scape (Fig. 1); basal flagellomeres cylindrical (Figs 1-3); first flagellomere 1.8 times as long as second (Fig. 2); ascoids observed only on third flagellomere of paratype (\#43950), short, 0.36 times as long as flagellomere (Fig. 3); palpus formula $=1.0: 0.7: 0.7: 0.7$ (Fig. 4). Wing (Fig. 5): distal end of Sc, base of $\mathrm{M}_{3}$, base of $\mathrm{CuA}_{1}$ and transversal vein m-cu lightly sclerotinized; CuA short, not reaching wing margin. Tergite 9 pilose (Fig. 6), wider than long; cerci with apical micropilosity and some bristles on apical margin (Fig. 6). Sternite 10 with apex narrower than base and with apical micropilosity (Fig. 6). Gonocoxite pilose, cylindrical, 1.4 times as long as gonostylus (Fig. 7). Gonostylus pilose with long spine at apex (Fig. 7). Parameres pilose, each with middle acute internal projection; projections not crossing each other (Fig. 8); presence of long, thick apical bristle twice as long as paramere (Fig. 8). Gonostylus with one apical spine slightly shorter than the gonostylus itself (Fig. 7); base of gonostylus with internal group of short sensorial setae (Fig. 7). Aedeagus bifid without pair of lateral sclerotinized projections. Aedeagal apodeme as long as gonostylus; anterior end of aedeagal apodeme bulbous (Fig. 9). 

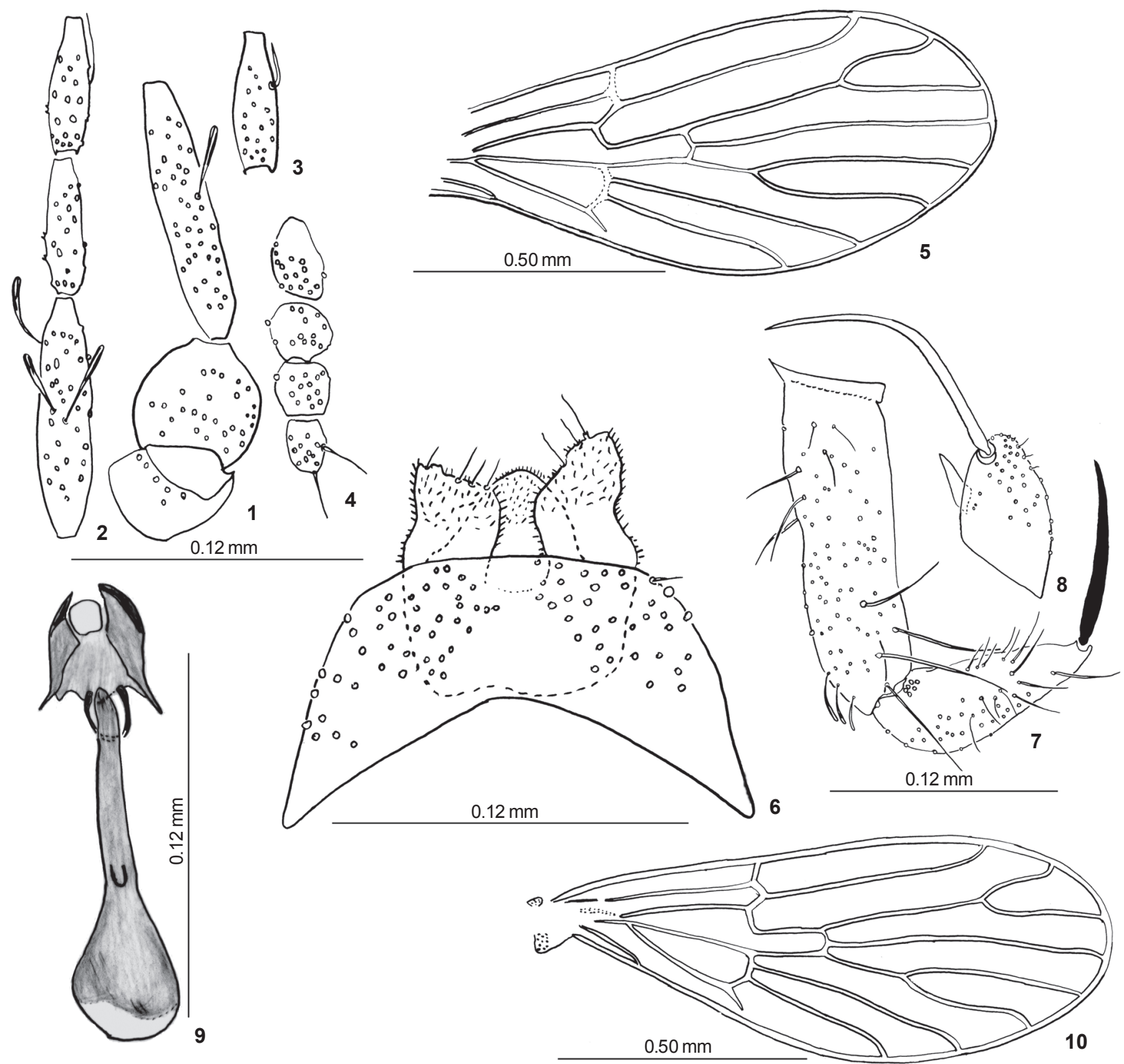

Figures 1-10. (1-9) Sycorax confusa sp. nov., male (1, 2, 4-9 holotype; 3 paratype \#43950): (1) antenna: scape, pedicel and basal flagellomere; (2) antenna: flagellomeres 2-4; (3) flagellomere 3 with ascoid; (4) palpus maxillaris; (5) wing; (6-8) male terminalia: (6) epandrium, cerci and sternite 10; (7) gonocoxite and gonostylus; (8) paramere with long bristle; (9) aedeagus and aedeagal apodeme; (10) Sycorax longispinosa paratype wing.

Female unknown.

Etymology. The name confusa, Latin for 'confused or mixed', was chosen because the species was initially confused with Sycorax longispinosa.

Remarks. Sycorax confusa sp. nov. (from the Atlantic Rain Forest of Espírito Santo) is morphologically similar to $S$. longispinosa (from the Amazonian Forest in Pará). The presence of a long, thick bristle in the paramere, twice as long as the latter (Fig. 8; Bravo 2007: fig. 10), is a putative synapomorphy for both species, absent in other Sycorax species. It is important to note that a basal group of short sensorial setae on the inner base of the gonostylus of the new species has also been observed 
in S. longispinosa; although this characteristic was not mentioned in the original description by BRAVo (2007), a careful examination of four paratype males deposited in MZUEFS has confirmed the presence of these sensorial setae. The new species and $S$. longispinosa can be distinguished from each other by the following characteristics: 1 ) the distal end of the Sc, the base of $M_{3}$, the base of $\mathrm{CuA}_{1}$ and the transversal m-cu vein are lightly sclerotinized in $S$. confusa sp. nov. (Fig. 5). While these veins are well sclerotinized in S. longispinosa (Fig. 10; Bravo 2007: fig. 5) the wing veins of $S$. longispinosa have been mistakenly interpreted as the base of $\mathrm{M}_{1+2}$; the correct interpretation is herein indicated in figure $10 ; 2$ ) the dorsal profile of the aedeagal apodeme of $S$. longispinosa is thin (Bravo 2007: fig. 9), whereas it is club-shaped in the new species (Fig. 9); 3) the middle acute internal projections of each paramere cross each other in S. longispinosa (Bravo 2007: fig. 9), but do not cross each other in the new species; 4) a pair of lateral sclerotinized projections of the aedeagus, similar to thin horns (Bravo 2007: figs 7, 9), which are present in $S$. longispinosa, are absent in the new species (Fig. 9).

\section{Key to males of Sycorax (sensu DuckHouse 1972) from the Neotropical Region}

1. Gonostylus with apical spine and two or three basal spines...2

$1^{\prime}$. Gonostylus with apical spine but without basal spines ... 6

2. Gonostylus with apical spine and three basal spines .......... S. andicola Young, 1979

2 '. Gonostylus with apical spine and two basal spines ......... 3

3. Gonostylus and gonocoxite without long subterminal hair; genital filament (see Bravo \& Salazar-Valenzuela 2009: fig. 11) sinuous S. trispinosa Young, 1979

3'. Gonostylus and gonocoxite with long subterminal hair; genital filament sinuous or arched .. 4

4. Genital filament sinuous ........ S. colombiensis Young, 1979

4 '. Genital filament arched .. 5

5. Lower distal end of paramere terminating in a hook-like projection, acute at tip; aedeagus ending at same level of distal end of genital filament ...... S. fairchildi Young, 1979

5 '. Lower distal end of paramere without hook-like projection, acute at tip; aedeagus ending before distal end of genital filament....S. wampukrum Bravo \& Salazar-Valenzuela, 2009

6. Paramere with long, thick bristle, 2 times the length of the paramere 7

6'. Paramere without long, thick bristle ................................ 8

7. First flagellomere long, 1.5 times the length of second flagellomere and twice as long as the third flagellomere; distal end of Sc, base of $\mathrm{M}_{3}$, base of $\mathrm{CuA}_{1}$ and transversal $\mathrm{m}$-cu vein well sclerotinized; presence of pair of lateral sclerotinized projections of aedeagus, similar to thin horns... S. longispinosa Bravo, 2007

7 '. First flagellomere short, 1.3 times the length of second flagellomere and 1.5 times the length of third flagellomere; distal end of $\mathrm{Sc}$, base of $\mathrm{M}_{3}$, base of $\mathrm{CuA}_{1}$ and transversal m-cu vein ligthly sclerotinized; without pair of lateral sclerotinized projections of aedeagus .. S. confusa sp. nov.

8. First flagellomere 1.3 times the length of second one ......... S. cariacicaensis Santos \& Bravo, 2009

8 '. First flagellomere 1.7-2.1 times the length of second one.....9

9. Parameres wide and long in dorsal view, the same length as the gonopods (gonocoxite + gonostylus) S. bahiensis Bravo, 2003

9'. Parameres shorter than gonopods 10

10. Aedeagus terminating in a hook-like projection, acute at tip S. assimilis Barretto, 1956

$10^{\prime}$. Aedeagus not terminating in a hook-like projection ....... S. espiritosantensis Santos \& Bravo, 2009

\section{ACKNOWLEDGMENT} 2006-4).

FB received a research grant from CNPq (Process 306426/

\section{LITERATURE CITED}

Barretto, M.P. 1956. Sobre o gênero Sycorax Hal., com as descrições de duas novas espécies do Brasil (Diptera, Psychodidae). Folia Clinica et Biologica 26 (1/6): 71-78.

Barretto, M.P. \& J.O. Coutinho. 1940. Processos de captura, dissecação e montagem de flebótomos. Anais da Faculdade de Medicina da Universidade de São Paulo 16: 173-187.

Bravo, F. 2003. Descrição de Sycorax bahiensis sp. nov. (Diptera, Psychodidae) do Brasil. Revista Brasileira de Zoologia 20 (3): 385-387.

Bravo, F. 2007. First Record and Description of a New Species of Sycorax Curtis (Diptera: Psychodidae, Sycoracinae) from the Brazilian Amazon. Neotropical Entomology 36 (4): 525528.

Bravo, F. \& D. Salazar-Valenzuela. 2009. A new species of Sycorax Curtis (Diptera, Psychodidae, Sycoracinae) collected on harlequin frogs (Anura: Bufonidae, Atelopus) in the Ecuadorian Andes. Zootaxa 2093: 37-42.

Duckhouse, D.A. 1972. Psychodidae (Diptera, Nematocera) of South Chile, subfamilies Sycoracinae and Trichomyinae. Transactions of the Royal Entomological Society of London 124 (3): 231-268.

JežEK, J. 1999. Comments on the correct grammatic gender of Sycorax Curt. and Philosepedon Eat. (Diptera: Psychodidae) with world catalogue. Diptera Bohemoslovaca 9: 83-87.

Santos, C.B. \& F. Bravo. 2009. Description of two new species of Sycorax Curtis (Diptera, Psychodidae, Sycoracinae) from the Atlantic Rain Forest of Espírito Santo, Brazil. Biota Neotropica 9 (2): 1-4.

Submitted: 04.II.2010; Accepted: 02.IV.2010.

Editorial responsibility: Gabriel L.F. Mejdalani 